\title{
Molecular Detection of CTX-M Genes in ESBL Producing Escherischia Coli Isolated from Various Clinical Samples
}

\author{
Kavitha. ${ }^{1}$, Suneetha. $C^{2}$, Indra Priyadharsini. $\mathbf{R}^{3}$ \\ ${ }^{1}$ Associate Professor, Department of Microbiology, VMKVMC, Salem. \\ ${ }^{2}$ Clinical Microbiologist, Chennai. ${ }^{3}$ Professor and Head, Department of Microbiology, VMKVMC, Salem.
}

\begin{abstract}
Introduction: There has been an increased emergence of ESBLs serving as a cause of failure of beta lactam therapy leading to increased morbidity and mortality. A study was conducted to identify CTX-M group of ESBLs among Escherichia coli isolated from various clinical samples collected at a tertiary care hospital using multiplex polymerase chain reaction.

Aims \& Objectives: Phenotypic detection and confirmation of ESBL E.coli and detection of bla CTX-M gene by Multiplex PCR.

Materials \& Methods: During the period from April 2013 to May 2014, clinical isolates of E.coli were collected and Antibiotic Susceptibility Testing (AST) was done according to Clinical Laboratory Standards Institute (CLSI) guidelines. Phenotypic screening and confirmation of ESBL production were done by Double Disc Synergy Test (DDST), Phenotypic Confirmatory Disc Diffusion Test (PCDDT) and E-test. Genotypic confirmation was done by Multiplex PCR for the presence of bla CTX-M genes.
\end{abstract}

Results: Out of the total 214 isolates, 133 showed resistance to at least one of the third generation cephalosporins. Primary phenotypic tests, DDST revealed 75 isolates and PCDDT revealed 93 isolates to be ESBL producers. 97 isolates were confirmed to be ESBL producers by E test and these 97 isolates were positive for CTX-M group 1 genes by Multiplex PCR.

Conclusion: The study demonstrated that Multiplex PCR is a rapid method for detection of bla CTX-M genes and CTX-M group 1 are the commonest among E.coli isolates in our hospital.

Keywords: ESBL E.coli, Double Disc Synergy, PCDDT, ESBL E-test, Multiplex PCR, CTX-M group 1 genes.

\section{INTRODUCTION:}

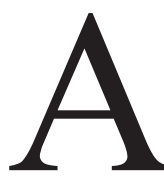
ntibiotic resistance is increasing at alarming levels and has emerged as a major public health concern of the $21 \mathrm{st}$ century. $\beta$-lactams are among the commonly used classes of antibiotics. Extended spectrum $\beta$ lactamases (ESBLs) are enzymes commonly produced by many members of Enterobacteriaceae especially Escherichia coli and Klebsiella pneumonia. They efficiently hydrolyse oxyiminocephalosporins conferring resistance to third generation cephalosporins such as Cefotaxime, Ceftazidime and Ceftriaxone as well as monobactems such as Aztreonam and are inhibited by Clavulanic acid, Tazobactam or Sulbactam. ${ }^{1}$ They serve as a clinical threat leading to failure of beta lactam therapy and extended hospitalisation with increased morbidity and mortality. ${ }^{2}$ They are a matter of concern as most of these enzymes are plasmid coded accounting for 
rapid dissemination as well as multidrug resistance especially to quinolones, aminoglycosides and Trimetoprim-sulphamethoxazole. ${ }^{3}$

Risk factors for infection with ESBL producing organisms are prolonged antibiotic usage, ICU stay, recent invasive procedure, pressure sores, anaemia and permanent urinary catheter. ${ }^{4}$ Effective and rational usage of antibiotics is important for prevention of development of antibiotic resistance. ESBL producing strains remain undetected as they are difficult to detect by routine susceptibility testing methods and may show false susceptibility to antibiotics by Kirby Bauer disc diffusion methods. ESBL detection is important as knowledge about its prevalence is helpful to formulate infection control measures and to prevent their spread.

Though the prevalence of E.coli has been recognized and reported from various parts of the country, there is limited data about its genotypes. Degree of resistance against third-generation cephalosporins can be highly variable among different ESBL enzymes and phenotypic methods cannot differentiate ESBL types. Molecular methods like isoelectric focussing, PCR and DNA sequencing need to be used for detection and typing of differentESBL enzymes.

\section{AIMS \& OBJECTIVES :}

1. Isolation and identification of E.coli from various clinical samples.

2. Determining their antibiotic susceptibility pattern.

3. Screening and confirmation of ESBL by DDST, PCDDT and E test.

4. Detection of bla CTX-M gene by Multiplex PCR.

\section{MATERIALS AND METHODS:}

A total of 214 E.coli isolates from various clinical specimens collected during the period of April 2013 to May 2014 were screened for ESBL activity.

Routine antimicrobial susceptibility testing was done using Himedia discs such as Amoxyclav $(20 \mu \mathrm{g}+10 \mu \mathrm{g})$, Cefotaxime $(30 \mu \mathrm{g})$, Ceftazidime $(30 \mu \mathrm{g})$, Ciprofloxacin $(5 \mu \mathrm{g})$, Cotrimoxazole $(25 \mu \mathrm{g})$ and Amikacin $(30 \mu \mathrm{g})$. Those resistant to third generation cephalosporins were chosen for detection and confirmation of ESBL production. ${ }^{5}$

\section{Double Disc Synergy Test (DDST): ${ }^{6}$}

E.coli that showed resistance to at least one of the third generation cephalosporins were screened for ESBL production by a modified double disc synergy test (disc approximation test) in which Amoxyclav disc was placed in the centre and Cefotaxime and Ceftazidime discs were placed on either side at a distance of $20 \mathrm{~mm}$ centre to centre from the Amoxyclav disc . Plates were incubated at $37 \circ \mathrm{C}$ for $18-20 \mathrm{hrs}$ and the pattern of zones of inhibition noted. Isolates which showed a zone of inhibition with a distinct size or shape with potentiation towards Amoxyclav disc were considered to be potential ESBL producers and subjected for confirmatory tests.

\section{Phenotypic Confirmatory Disc Diffusion Test (PCDDT): ${ }^{7}$}

Sensitivity testing was performed using third generation cephalosporin discs alone as well as in combination with clavulanic acid, a betalactamase inhibitor. A difference in zone diameters between discs with or without clavulanic acid was recorded. Isolates that showed an increase of $\geqslant 5 \mathrm{~mm}$ of zone diameter with the combination disc were confirmed phenotypically to be positive for ESBL production. 


\section{ESBL E-Test: ${ }^{8}$}

The E-test ESBL strips (AB Biodisk, Sweden) carry two gradients, Ceftazidime $(0.5-32 \mu \mathrm{g} / \mathrm{ml})$ on the one end and Ceftazidime plus Clavulanic acid $(0.064-4 \mu \mathrm{g} / \mathrm{ml})$ in a different concentration gradient on the other end, along with a fixed concentration of Clavulanic acid $(4 \mu \mathrm{g} / \mathrm{ml})$. A lawn culture of the test organism was made on Mueller Hinton Agar (MHA) on which the E-test ESBL strip was placed on the centre of the plate. The plates were incubated aerobically at $37^{\circ} \mathrm{C}$ for $16-18$ hours. The MIC was interpreted at the point of intersection of the inhibition eclipse with the E-test strip edge. The presence of ESBL was confirmed by the appearance of a phantom zone or by the deformation of the eclipse or when the Ceftazidime MIC was reduced by $>3 \log 2$ dilutions in the presence of Clavulanic acid as per the manufacturer's guidelines.

\section{Multiplex PCR assay for detection of CTX-M genes: ${ }^{9}$}

A multiplex-PCR was performed to screen the presence of five phylogenetic groups of bla CTX$\mathrm{M}$ genes. DNA was prepared by emulsifying 2-5 colonies in $100 \mu \mathrm{l}$ of molecular- grade water (Qiagen, Germany); $1 \mu 1$ of the DNA template was added to $20 \mu \mathrm{l}$ of the $\mathrm{PCR}$ reaction mixture (Invitrogen, USA). The cycling conditions were: initial DNA release and denaturation at $94^{\circ} \mathrm{C}$ for 5 min, followed by 30 cycles of $94^{\circ} \mathrm{C}$ for $30 \mathrm{sec}, 52^{\circ} \mathrm{C}$ for $40 \mathrm{sec}$ and $72^{\circ} \mathrm{C}$ for $50 \mathrm{sec}$, followed by a final elongation step at $72^{\circ} \mathrm{C}$ for $6 \mathrm{~min}$. The PCR products were analyzed by gel electrophoresis with $2 \%$ agarose in TBE buffer with Ethidium bromide $(5 \mu \mathrm{g} / \mathrm{ml})$ and visualized by UV-transillumination. A 100bp DNA ladder (Invitrogen, USA) was used as a marker. Multiplex-PCR yielded the product with size of $415 \mathrm{bp}$ which corresponded to group1 bla CTX-M genes. PCR-products were purified from the gel and sequenced on both strands by big dye chain termination method for further confirmation.

\begin{tabular}{|c|c|c|}
\hline Group of CTX-M genes & Primer sequences & PCR product size \\
\hline Group 1 & $\begin{array}{c}\text { F-AAAAATCACTGCGCCAGTTC } \\
\text { R-AGCTTATTCATCGCCACGTT }\end{array}$ & $415 \mathrm{bp}$ \\
\hline Group 2 & $\begin{array}{c}\text { F-CGACGCTACCCCTGCTATT } \\
\text { R-CCAGCGTCAGATTTTCAGG }\end{array}$ & $552 \mathrm{bp}$ \\
\hline Group 9 & $\begin{array}{c}\text { F- AAAGAGAGTGCAACGGATG } \\
\text { R-ATTGGAAAGCGTTCATCACC }\end{array}$ & $205 \mathrm{bp}$ \\
\hline Group 8 & $\begin{array}{c}\text { F-TCGCGTTAAGGGGATGATGC } \\
\text { R-AACCCACGATGTGGGTAGC }\end{array}$ & $666 \mathrm{bp}$ \\
\hline Group 25 & $\begin{array}{c}\text { F-GCACGATGACATTCGGG } \\
\text { R-AACCCACGATGTGGGAGC }\end{array}$ & $327 \mathrm{bp}$ \\
\hline
\end{tabular}

\section{RESULTS:}

Out of a total number of 214 E.coli isolates, maximum were collected from urine (64.5\%) followed by pus and sputum (11.7\% each), and wound swab (8.8\%) (Figure 1).

\section{Figure 1. Distribution of E.coli among clinical samples}

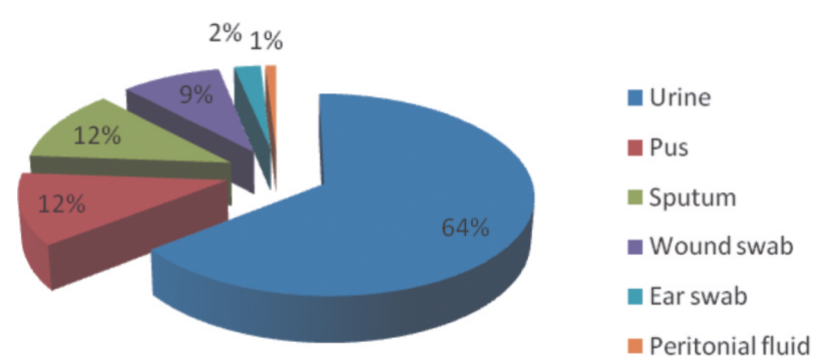

\section{Antibiotic Susceptibility Pattern:}

Maximum resistance was observed for Cotrimoxazole (67.8\%) followed by Ciprofloxacin $(57.5 \%)$. The rate of resistance to Cefotaxime and Ceftazidime were in the order of $56.1 \%$ and $52.8 \%$ respectively. The minimum resistance was 
observed for Piperacillin -Tazobactem (2.8\%) and Amikacin (7.9\%). All the isolates were susceptible to Imipenam (100\%) (Figure 2).

Figure 2: Antibiotic Susceptibility Pattern of E.coli

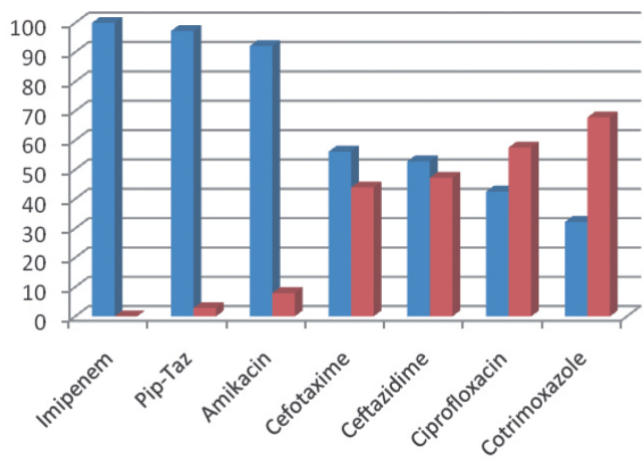

- Sensitive - Resistant

\section{ESBL Detection:}

Out of the total number of 214 E.coli isolates, 133 $(62 \%)$ showed resistance to one of the third generation cephalosporins, 75 (35\%) were positive for ESBL production by double disc synergy test (DDST) while 93 (43\%) were positive by phenotypic confirmatory combination disc diffusion method (PCDDT). Further testing by E test for Cefotaxime showed 97 (45\%) to be positive for ESBL production (Figure 3).

\section{Figure 3: ESBL producers among E.coli}

\begin{tabular}{|l|c|c|}
\hline \multicolumn{1}{|c|}{ Test } & Numbers & Percentage \\
\hline DDST & 75 & $35 \%$ \\
\hline PCDDT & 93 & $43 \%$ \\
\hline E- test & 97 & $45 \%$ \\
\hline
\end{tabular}

\section{PCR:}

Multiplex PCR was done for all 97 E-test ESBL positive isolates and all were positive for bla CTXM group I genes.

\section{DISCUSSION:}

The overall prevalence of ESBL producers was found to vary greatly in different geographical areas and in different institutes. In the present study, the prevalence of ESBL-producing isolates of E.coli was found to be $45 \%$. Previous studies from India have reported ESBL production varying from $6 \%$ to $87 \%$. $^{10,11,12,13,14}$ One reason for such variability may be the very low number of samples studied. Worldwide, a significant increase in ESBL producers was reported from USA, ${ }^{15}$ Canada, ${ }^{16}$ China, ${ }^{17}$ and Italy. ${ }^{18}$ A large survey of from 31 centres in 10 European countries found that the prevalence of ESBL in these organisms ranged from as low as $1.5 \%$ in Germany to as high as 39$47 \%$ in Russia, Poland, and Turkey. ${ }^{19}$

Regarding the methods of ESBL detection, DDST showed 35\% positivity and PCDDT showed 43\% positivity. Among the two methods, PCDDT was more sensitive than DDST which is similar to the studies done by MKR Khan et $\mathrm{al}^{20}$ at New Delhi and Dhara Modi et $\mathrm{al}^{21}$ at Ahmedabad. This could be due to the co-existence of AmpC masking the presence of ESBL. Decreased sensitivity of the tests can be explained by the presence of strains which produce both ESBL \& inducible AmpC enzymes. Clavulanic acid which was used in the standard tests for ESBL detection act as inducers of high level AmpC production and it led to resistance to 3rd generation cephalosporins as well 3rd generation Cephalosporins + Clavulanic acid. So even if ESBL was present, it would not be detected and resulted in false negative test. A negative ESBL confirmatory test using Clavulanate as the inhibitor may be interpreted as an indication of AmpC production.

A high degree of co-resistance to Co-trimaxazole and Norfloxacin was found in strains of ESBL E.coli in our study. Malhotra et $\mathrm{al}^{22}$, Bishara et $\mathrm{al}^{23}$, Kronenberg et $\mathrm{al}^{24}$ and Baby Padmini et $\mathrm{al}^{25}$ also showed similar results in their studies. This will 
further limit the available oral therapeutic options. Higher incidence of resistance to these drugs might be due to Escherichia coli being the most common pathogen isolated and frequent usage of these drugs in the treatment of urinary tract infections. Increased association of resistance to these drugs among the ESBL producers suggest a strong possibility of plasmid mediated multidrug resistance. $^{26}$

All the isolates which are positive for CTX-M group I were however negative for CTX-M group II, III and IV. This pattern of results is similar to a study conducted at our institute by R.Indra Priyadharsini et al who also found all of their isolates to be positive for the CTX-M group I genes indicating that this is the most common type of CTX-M genes present in our hospital set up. ${ }^{27}$ Other studies conducted by Shahid et $\mathrm{al}^{28}$ and Iroha et $\mathrm{al}^{29}$ showed all of their strains also to be positive for CTX-M-1 cluster and studies by Al-Agamy et $\mathrm{al}^{30}$ from Riyadh and Peirano et $\mathrm{al}^{31}$ from from Chicago documented the high prevalence of ESBLs in E.coli isolates, with CTX-M-15 which also belongs to CTX-M group I as the predominant ESBL gene.

It is recommended that these samples be subjected to further testing such as plasmid profiling so as to detect the likelihood of single clone dissemination as well as to trace the common source of infection. ${ }^{32}$

Molecular epidemiology of ESBL producing E.coli at this hospital will be more representative of an endemic persistence of clones of the organism with limited dissemination from patient to patient. Further studies to investigate the factors which determine the emergence and persistence of MDR ESBL producing E.coli would be useful.

\section{Limitations of the study:}

We did not test for AmpC and metallo beta lactamse (MBL) and the study was done in only one centre. Future studies should be multicentric and should include testing for AmpC and metallo beta lactamse (MBL).

\section{CONCLUSION:}

The prevalence of ESBL E.coli at our institute is $45 \%$. It is recommended that along with conventional antibiogram, routine ESBL testing should be done. Phenotypic Confirmatory Disc Diffusion Test using the combination method proves to be very useful for the detection of ESBL producers especially in routine antibiotic susceptibility testing.

The prevalence of multidrug-resistant E.coli is quite high in our hospital and notably, an increasing proportion of ESBL E.coli show co-resistance to both Trimethoprim-Sulfamethoxazole and Quinolones. Presently, Piperacillin - Tazobactem combination and Amikacin drugs are to be considered as effective therapeutic options for the treatment of ESBL producers and Imipenem should be considered as reserve drug for future use.

This study emphasizes the major role that CTX-M1 plays in facilitating ESBL-mediated antimicrobial resistance in our institute and reiterates its association with multiple antibiotic resistance. Multiplex PCR is a rapid and efficient method for molecular detection of CTX-M group of enzymes. PFGE and Plasmid profiling will help in identifying the actual source of disseminated clones.

Judicious use of antibiotics and implementation of appropriate infection control measures are needed to control the spread of these strains in the hospital. 


\section{REFERENCES:}

1. Jacoby GA, Mediros AA. More Extended spectrum beta lactamases. Antimicrob agents chemother 1991; 35:1697-1704.

2. Schwaber MJ,Navon venezia S, Kaye KS, Ben Ami R, Schwartz D and CarmeliY. Bacteremia with Extended spectrum beta lactamase producing Enterobacteriaceae. Antimicrob agents chemother 2006; 50:1257-1262.

3. Nipa Singh, Dipti Pattnaik, Dhruba Kumar Neogi, Jagadananda Jena, and Bandana Mallick. Prevalence of ESBL in Escherichia coli isolates among ICU Patients in a tertiary care hospital. J Clin Diagn Res. Sep 2016; 10(9):19-22.

4. Jemina SA and Susan Verghese. Multiplex PCR for bla CTX-M and bla SHV in Extended spectrum beta lactamase (ESBL) producing Gram negative isolates. Indian J Med Res, Sep 2008; 128(3):313-7.

5. Screening tests for ESBLs in Escherichia coli and Klebsiella spp. Clinical Laboratory Standards Institute (CLSI) Jan 2013; M100S23:45-51.

6. Kumar.M.S, Lakhsmi.V, Rajagopalan.R. Occurrence of Extended spectrum beta lactamases among Enterobacteriaceae isolated at a tertiary care institute. Indian $\mathrm{J}$ Medical Microbial 2006; 24: 208-211.

7. Performance standards of Antimicrobial disc Susceptibility tests. Clinical Laboratory Standards Institute (CLSI), Jan 2012; M 100S22:50-51.
8. Gaurav Dalela. Prevalence of Extended spectrum $\beta$ lactamase (ESBL) producers among Gram negative bacilli from various clinical isolates in a tertiary care hospital at Jhalawar, Rajasthan, India. Journal of Clinical and Diagnostic Research. April 2012; 6(2):182-187.

9. Woodford N, Fagan EJ, Ellington MJ. Multiplex PCR for rapid detection of genes encoding CTX-M Extended spectrum $\beta$ lactamases. J. Antimicrobial Chemother 2005; 10:154-155.

10. Mathur P, Kapil A, Das B, Dhawan B. Prevalence of Extended spectrum $\beta$ lactamases producing Gram negative bacteria in a tertiary care hospital. Indian J Med Res 2002; 115:153-7.

11. Hansotia JB, Agarwal V, Pathak AA, Saoji AM. Extended spectrum $\beta$ lactamase mediate resistance to third generation cephalosporins in Klebsiella pneumoniae in Nagpur, central India. Indian J Med Res 1997; 105:160-5.

12. Manchanda V, Singh NP, Goyal R, Kumar A, Thukral SS. Phenotypic characteristics of clinical isolates of Klebsiella pneumoniae and evaluation of available techniques for detection of Extended spectrum $\beta$ lactamases. Indian J Med Res2005; 122:330-7.

13. Tankhiwale SS, Jalgaonkar SV, Ahamad S, Hassani U. Evaluation of Extended spectrum beta lactamase in urinary isolates. Indian $\mathrm{J}$ Med Res 2004; 120:553-6.

14. Jain A, Roy I, Gupta MK, Kumar M, Agarwal SK. Prevalence of extended spectrum $\beta$ lactamase producing Gram negative bacteria in septicaemic neonates in a tertiary care hospital. J Med Microbiol 2003; 52:421-5. 
15. Saurina G, Quale GM, Manikal VM, Oydna E, Landman D. Antimicrobial resistance in Enterobacteriaceae in Brooklyn NY: Epidemiology and relation to antibiotic usage patterns. J Antimicrob Chemother 2000; 45:895-8.

16. Cordero L, Rau R, Taylor D, Avers LW. Enteric Gram negative bacilli blood stream infections: 17 years experience in a neonatal intensive care unit. Am J Infect Control 2004; 32:18995.

17. Xiong Z, Zzhu D, Zhang Y, Wang F. Extended spectrum beta-lactamase in Klebsiella pneumoniae and Escherichia coli isolates. Zhongua Yi Xue Za Zhi 2002; 82:1476-9.

18. Luzzaro F, Mezzatesta M, Mugnaioli C, Perilli M, Stefani S, Amicosante G, et al. Trends in production of Extended Spectrum BLactamases among Enterobacteria of medical interest: Report of the second Italian nationwide survey. J Clin Microbiol 2006; 44:1659-64.

19. Goosens H. MYSTIC programme: Summary of European data from 1997 to 2000. Diagn Microbiol Infect Dis 2001; 41:183-9.

20. MKR Khan, SS Thukral, R Gaind. Evaluation of a Modified Double-Disc Synergy test for detection of Extended spectrum $\beta$ Lactamases in AmpC $\beta$ lactamase producing Proteus mirabilis. Indian Journal of Medical Microbiology. 2008;26(1): 58-61.

21. Dhara Modi, Disha Patel, Sachin Patel, Manisha Jain, Seema Bhatt, M M Vegad. Comparison of various methods for the detection of Extended spectrum beta lactamase in Klebsiella Pneumoniae isolated from Neonatal intensive care unit, Ahmedabad. National Journal of Medical Research. 2012;2(3): 348-353.

22. Malhotra VL, Khandpur N, Dass A, Mehta G. Prevalence of extended spectrum betalactamases producing clinical isolates from patients of urinary tract infection in a tertiary care hospital in Delhi. J Commun Dis. 2008 Dec; 40(4):269-72.

23. Bishara J, Livne G, Ashkenazi S, Levy I, Pitlik S, Ofir O, Lev B, Samra Z. Antibacterial susceptibility of Extended spectrum $\beta$ lactamase producing Klebsiella pneumoniae and Escherichia coli. ISR Med Assoc J. May 2005; 7(5):298-301.

24. Kronenberg A, Hilty M, Endimiani A, Mühlemann K. Temporal trends of extendedspectrum cephalosporin-resistant Escherichia coli and Klebsiella pneumoniae isolates in inand outpatients in Switzerland, 2004 to 2011. Euro Surveill. 2013;18(21):1-10

25. Babypadmini S, Appalaraju B. Extended spectrum $\beta$ lactamases in urinary isolates of Escherichia coli and Klebsiella pneumoniae Prevalence and susceptibility pattern in a tertiary care hospital. Indian J Med Microbiol. 2004; 22:172-74.

26. Mirazee M, Pourmand MR, Chitsaz M, et al. Antibiotic resistance to third generation cephalosporins due to CTX-M type Extended spectrum $\beta$ lactamases in clinical isolates of Escherichia coli. Iranian J Public Health 2009; 38:10-17. 
27. Indra Priyadarshini R, Kavitha A, Reena Rajan, Mathavi S and Rajesh KR. Prevalence of bla CTX-M Extended spectrum $\beta$ lactamase gene in Enterobacteriaceae from critical care patients. J. Lab physicians, 2011 Jul-Dec; 3(2):80-83.

28. Shahid M, Singhal M, MalikA, Shukla I, Khan HM. ESBL phenotypes and prevalent genotype of CTX-M type beta lactamases in clinical isolates of E.coli in a North Indian tertiary care hospital. Proceedings of MICROCON 2006. XXX National Congress of Indian Association of Medical Microbiologists, 2006; October 27-29, Government Medical College, Nagpur, OB17:27.

29. Ifeanyichukwu R Iroha, Charles O Esimone, Sandra Neumann, Lennart Marlinghaus, Miriam Korte, Florian Szabados, et al. First description of Escherichia coli producing CTX-M-15-Extended spectrum beta lactamase (ESBL) in out-patients from South Eastern Nigeria. Annals of Clinical Microbiology and Antimicrobials 2012; 11:19-23.
30. Al-Agamy MH, Shibl AM, Hafez MM, AlAhdal MN, Memish ZA, Khubnani $\mathrm{H}$. Molecular characteristics of Extendedspectrum $\beta$ lactamase producing Escherichia coli in Riyadh: emergence of CTX-M-15producing E.coli ST131. Annals of Clinical Microbiology and Antimicrobials, 2014 Jan 7; $13: 4$.

31. Peirano G, Costello M, Pitout JD. Molecular characteristics of extended spectrum beta lactamase producing Escherichia coli from the Chicago area: high prevalence of ST131 producing CTX-M-15 in community hospitals. Int J Antimicrob Agents. 2010 Jul; 36(1):19-23.

32. Struelens MJ. Consensus guidelines for appropriate use and evaluation of microbial epidemiologic typing system. Clin Microbial Infect.1996;2(1):2-11.

Received on 24/04/2017 Revised on 04/12/2017 Accepted on 05/12/2017 